\title{
Polis \\ Revista de la Universidad Bolivariana \\ La república legítima \\ y el orden político en Rousseau: principios de composición e imagen del estado de equilibrio
}

\author{
Augusto Bolívar Espinoza* \\ Óscar Cuéllar Saavedra*
}

\begin{abstract}
Resumen: Este trabajo examina el Contrato social de Rousseau como exposición de los principios de derecho político de la "república legítima" (Estado), que están en la base de la comprensión de los cuerpos políticos modernos. Tomando en cuenta el campo agonístico de la teoría del contrato y de la tradición republicana en que se inserta, el interés recae en la identificación y sistematización de los principios formales que subyacen a su concepción de la república como un todo compuesto y complejo, así como al enunciado de sus principios constitutivos. A partir de ello, el artículo identifica el modelo de la república en estado de equilibrio, que le permite dar el paso para el desarrollo de su teoría sobre el funcionamiento del Estado y el papel del gobierno.
\end{abstract}

Palabras clave: contrato social, república legítima, teoría del Estado

\section{The legitimate republic and political order in Rousseau: principles of composition} and image of de state of equilibrium

Abstract: The article analizes Rousseau's Social Contract as a treatise on the principles of political law and the "legitimate republic" (State), which are important for the understanding of modern political bodies. Within the background of the social contract theory and republican tradition, the authors center on the formal principles underlying the idea of "legitimate republic" as a complex whole and the principle of popular sovereignty. They then proceed to identify the model of equilibrium as a nexus between the general theory and Rousseau's more empirical hypothesis on the functioning of the State and the government.

Key words: social contract, legitimate republic, theory of the State

Recibido: $30.10 .07 \quad$ Aceptado: 17.12 .07

$* * *$

\footnotetext{
*Universidad Autónoma Metropolitana, Unidad Azcapotzalco, Ciudad de México, México. Email: abe88@hotmail.com

*** Universidad Autónoma Metropolitana, Unidad Azcapotzalco, de Ciudad de México, México. Email: oscarcuellar00@prodigy.net.mx.
} 


\section{Introducción}

Este trabajo se inserta en el ámbito de estudio de los principios y procedimientos de construcción orientados a pensar el orden político, desde los inicios de la modernidad y que culminan con Rousseau. Este autor sentaría el modelo racional al que se referirán los esfuerzos epistemológicos y prácticos de su institución de fines del siglo XVIII. ${ }^{1}$ En este contexto, nos interesamos por un aspecto poco atendido de su obra; en particular, el que retoma su expresa indicación de que el Contrato social o Principios del Derecho Político es sobre todo una teoría del Estado. Esto se refleja en varios títulos posibles que Rousseau desechó, pero que dan una clara idea de cuál era el problema de fondo que le interesaba. Así, consideró llamarle la Société Civil, la Constitution de l' État, la Formation du corps politique, la Formation de l' État, la Forme de la République (Rousseau, 1997). Estos posibles títulos se refieren a los "principios del derecho político", en particular, de la "república legítima" o Estado, y se vinculan con su propósito declarado de "investigar si dentro del radio del orden civil, y considerando a los hombres tal cual ellos son y a las leyes tal cual pueden ser, existe alguna fórmula de administración legítima y permanente" (Contrato social, Libro I, cap. I; pág. 3). ${ }^{2}$

El presente trabajo se separa de las preocupaciones dominantes en los estudios sobre Rousseau. En efecto, la mayoría de ellos se ha centrado en unos cuantos temas: la posición y significado de su obra en el campo de la teoría del contrato social (por ej. Terrel, 2001; Riley, 1999; Sabine, 1990); la congruencia entre el Contrato social y otros escritos del autor (por ej., Riley, 1999; Derathé, 1997; Bloom, 1993; Rubio Carracedo, 1990); y la coherencia interna del propio Contrato (por. ej., Riley, 1999; 1970; más recientemente, en relación con sus ideas económicas, ver Valenzuela, 2006 y 2003). En cuanto a su significado para el futuro, si bien en general esta obra ha sido considerada como la justificación y defensa de la república democrática, algunos, por el contrario, la han visto como una fuente del totalitarismo del siglo XX (por ej., Talmon, 1955).

\footnotetext{
${ }^{1}$ Este trabajo se inscribe en el proyecto "Políticas Institucionales de Control", que forma parte del Grupo "Sociología de la política" del Departamento de Sociología de la División de Ciencias Sociales y Humanidades de la Universidad Autónoma Metropolitana, Unidad Azcapotzalco, de Ciudad de México. Corresponde a una primera fase cuyo objetivo específico es examinar críticamente las aproximaciones teóricas a la noción de "orden político", partiendo con las teorías del contrato social y llegando hasta la forma de la moderna república representativa. En esta fase, hemos puesto de relieve dos temas centrales, a saber: (1) los principios formales, sean teóricos o institucionales, que permiten pensar el orden político como totalidad. Aquí se trata de identificar los procedimientos de construcción del concepto de orden político como un todo coherente partiendo por el examen de las teorías sobre el Estado y lo político. (2) El segundo tema pone la mirada en las teorías que de allí pueden derivarse respecto del funcionamiento del Estado y del gobierno. Este trabajo se ubica dentro del primer tema.

${ }^{2}$ Usamos la versión española publicada por la editorial Porrúa, México, indicando primero las iniciales, seguidas del Libro, el capítulo y la página. Así, "CS, I; i: 3" = Contrato social, Libro I, capítulo I, página 3. En ocasiones agregaremos las iniciales N. T., que significan "nuestra traducción". Respecto de otras obras del autor, seguiremos el procedimiento convencional.
} 
La novedad relativa de este artículo consiste en un esfuerzo por poner de relieveprimero- las operaciones conceptuales y principios formales subyacentes a los planteamientos filosóficos e históricos explícitos de Rousseau, que permiten pensar al Estado como un todo y establecer los principios constitutivos de la "república legítima". Y segundo, por identificar el modelo de la república en estado de equilibrio, es decir, el modelo con el cual sienta las bases para analizar e interpretar fenómenos históricopolíticos, ahora en un plano más bien sociológico. Este esfuerzo involucra realizar una interpretación basada en una operación de "deconstrucción" y "reconstrucción", que respeta lo permanente de Rousseau y que exige distinguir entre diferentes niveles de abstracción y de generalización, mostrando la coherencia que hay entre ellos (Derrida, 1967: 15-21; Lyotard, 1994; Bergeron, 1996; Bolívar y Cuéllar, 2004).

La exposición parte ubicando la obra dentro del campo de discusiones sobre el orden político y el Estado constituido por las teorías del contrato social y la tradición republicana y resumiendo las hipótesis generales que orientan el trabajo. A continuación, examinamos la manera como Rousseau estableció las categorías básicas para el planteamiento de sus principios del derecho político, para luego presentar su teoría de la república legítima, a saber, la que se basa en el principio de soberanía popular. En la última sección sistematizamos y resumimos los principios formales que le permitieron tratar al Estado como un todo compuesto y complejo y exponemos el modelo de su estado de equilibrio. En las conclusiones hacemos algunas observaciones sobre el papel que dicho modelo juega en relación con su teoría del funcionamiento del Estado y del gobierno, referida al análisis e interpretación de los fenómenos histórico políticos.

Señalemos, por último, que si bien en la interpretación a veces hemos debido separarnos del lenguaje del autor e introducir otro más actual, en general nos hemos ceñido estrechamente al texto original.

\section{De la teoría del contrato a la teoría de la república legítima}

El terreno de fondo de la indagación y discusión filosófico-teórica que este artículo considera y el ámbito temporal en que se ubica, corresponden al de la problemática de la "ciencia y la filosofía política y civil" clásica, que parte con la obra de Hobbes (1984) -el cual integró en un solo campo las tradiciones intelectuales previamente separadas e independientes de la soberanía, el derecho natural y el pacto de asociación (Terrel, 2001) - para extenderse, en el plano filosófico, hasta la Metafísica de las costumbres de Kant y los Principios de la filosofía del Derecho de Hegel. Estos hitos marcan el propósito compartido de discernir críticamente las "consecuencias", los "principios" o las "condiciones" que están en la base de la comprensión del orden político y de su funcionamiento como un todo. Pero también y paralelamente, nuestra delimitación incluye la tradición -teórico-sociológica avant la lettre- que, entreverada 
con la anterior y subyacente a la idea republicana, se encuentra especialmente representada por Maquiavelo y Montesquieu (Skinner, 1993 y 1986). Estas tradiciones alcanzan un momento cúlmine en Rousseau, "fundador de las ciencias del hombre" (Lévy-Strauss, 1962), continuándose más tarde con los trabajos de análisis sociopolítico de El Federalista, de De Tocqueville y de J. S. Mill.

El interés por Rousseau surge del hecho de que él sintetiza ambas tradiciones, por un lado clausurando las discusiones sobre la obligación política características de la teoría del contrato y por otro, estableciendo la teoría de la "república legítima" o del Estado fundado en el principio de soberanía popular. Así da cimiento a la idea de un orden político propiamente republicano. En este sentido, Rousseau aparece como gozne o nexo que facilita el paso de un cierto momento del desarrollo teórico a otro nuevo, que no es solo teórico sino también práctico e institucional, que se inicia con la Constitución de la Unión Americana y la Revolución Francesa para extenderse hasta nuestros días. Pero también y no menos importante, nos ha interesado el hecho de que con su obra pone los cimientos de una aproximación sociológica al estudio del funcionamiento del Estado y del gobierno.

Conviene exponer brevemente la justificación de esta tesis general. La tradición contractualista puede caracterizarse como un esfuerzo, fundado en el principio de la dignidad humana, por dar cuenta del establecimiento de la sociedad y del Estado a partir de un hipotético contrato de hombres en "estado de naturaleza". En tanto ella coloca a la voluntad y a la acción humanas como fundamentos de la "obligación política" (del derecho a mandar y del deber de obedecer), rompe con tradiciones previas, que derivaban dicha obligación del imperio de la fuerza o de la voluntad divina. En efecto, sus planteamientos centrales comprenden: (1) la tesis de la igualdad y libertad naturales de los hombres; (2) la tesis sobre el carácter convencional tanto de la sociedad civil como del Estado y (3) el supuesto de que estos son la condición de posibilidad de una vida propiamente humana (Cuéllar y Bolívar, 2001).

La crítica de Rousseau apunta a mostrar y superar la inconsistencia lógica y moral que le atribuye, en especial a las versiones de Grotio y de Hobbes. En efecto, en su concepto si bien ella parte de los supuestos de igualdad y libertad naturales de los hombres, termina estableciendo y legitimando su sumisión al poder del soberano (con la salvedad de Locke). Así se pierden la igualdad y libertad iniciales de los hombres, que pasan a ser súbditos de un soberano absoluto. De acuerdo con Rousseau, desde un punto de vista lógico ello implica que en la teoría hay contradicción entre la primera tesis y la última, mientras que desde un punto de vista moral significa que se abandona el principio de la dignidad humana.

La reconstrucción que Rousseau hace de la teoría del contrato busca preservar la coherencia entre dichas tesis afirmando la primacía del principio de la dignidad humana. Esto lo logra modificando la forma del contrato y su cláusula central. A diferencia de 
otras versiones que distinguen entre dos pactos (uno de constitución del pueblo y otro de sumisión de este al gobierno) o bien que aceptan uno en que todos se obligan a entregar todo su poder a un tercero que no pacta (el "representante" o soberano, que es el gobernante), en la versión de Rousseau el contrato es de todos con todos e igual para todos, lo que significa: (a) que todos tienen los mismos derechos y las mismas obligaciones y (b) que quienes pactan dejan de ser una mera "multitud" o agregación, para instituirse como una "unión", es decir, en una persona moral distinta de sus creadores aunque compuesta por ellos. ${ }^{3}$ Lo primero excluye toda sumisión de los miembros a un tercero -al gobierno o soberano de otras versiones de la teoría-. Lo segundo significa que, dado que la unión es una persona moral compuesta por los asociados con iguales derechos y obligaciones, sólo ella es la condición para preservar la igualdad y la libertad de quienes pactan, sólo que ahora transformadas en libertad e igualdad civiles y morales (CS, I; vi: 9; CS, I; viii: 12).

Una consecuencia importante de esta operación es que lleva a redefinir el concepto de soberanía; otra, que coloca al gobierno como subordinado a la persona moral de la unión. Si en otras versiones del pacto social la soberanía es un atributo del gobernante, en la de Rousseau, que abreva en la tradición republicana, sólo puede ser atributo del cuerpo colectivo conformado por la unión de todos con todos. Por esto y dado que toda sociedad (Estado) requiere tener un gobierno, este sólo puede ser concebido como subordinado a la persona moral de la unión. Es en este sentido que Rousseau no sólo cierra el campo teórico-filosófico estructurado por Hobbes más de un siglo antes, sino que también, al establecer el principio de soberanía popular, sienta las bases del pensamiento moderno sobre el Estado y la política, que poco después encarnaría en las instituciones de la república popular representativa.

Pero Rousseau no sólo define los principios constitutivos del derecho político y de la "república legítima", sino que también le interesa hacerlo considerando "a los hombres tal cual ellos son y a las leyes tal cual pueden ser". Esto le lleva, por un lado, a a precisar el modelo de la república legítima en estado de equilibrio, es decir, a delinear un sistema de proposiciones que definen el tipo de exigencias que racionalmente deben darse para que la república legítima (es decir, el Estado) pueda en efecto -al menos teóricamente- considerarse como la condición de posibilidad del logro de la dignidad humana. Y por otro, a tomar en cuenta el medio natural y humano en que él se establece y que pueden tener incidencia en su funcionamiento.

Desde el punto de vista del proceso de "deconstrucción-reconstrucción" a que nos referimos antes, e independientemente del orden de la exposición de Rousseau, la tesis

\footnotetext{
${ }^{3}$ A diferencia de una "agrupación" o "multitud", que no es sino un conjunto de hombres que no constituye asociación ni sociedad, sino todo lo más "un señor y esclavos", la unión es una "asociación", una "sociedad", un "cuerpo político", una "persona moral" que tiene "bien público" (CS, I; v: 8).
} 
expuesta plantea tanto la exigencia de reconocer la importancia de la concepción de la unión como un todo como el hecho de que su análisis se despliega en planos de análisis diferentes, aunque vinculados, a saber: uno, de carácter más general y abstracto y otro más próximo al de la interpretación de los fenómenos histórico políticos. En el primero, la argumentación se desarrolla como construcción de la teoría de la "república legítima", mientras que el segundo presta especial atención a lo que Montesquieu (1971) llamó "clima" y al juego de la naturaleza humana. El nexo que vincula ambos planos de análisis y que permite pasar ordenadamente de un nivel de argumentación a otro está dado por su modelo de equilibrio. Tomados en conjunto, estos aspectos o momentos dan sentido y coherencia a sus planteamientos, diluyendo muchas de las afirmaciones de los comentaristas sobre las paradojas o incluso contradicciones al parecer insolubles de su pensamiento. ${ }^{4}$

\section{La unión}

¿Qué entiende Rousseau por “república legítima”? En breve, una república legítima es la forma de organización política -Estado- de un pueblo, que se basa en el principio de soberanía popular.

Esta determinación, demasiado esquemática, supone el desarrollo de un conjunto de conceptos o categorías articuladas, a saber, por una parte las de unión, asociación y pueblo, y por otra, las de república o Estado, soberanía y gobierno. El primer conjunto se centra en el examen del resultado del pacto de todos con todos, es decir, de la unión o en un lenguaje más laxo, pueblo- que Rousseau, siguiendo a Hobbes, opone a la mera "agregación" o "multitud", y a la cual, ahora separándose de este, considera desde dos puntos de vista: uno que destaca la naturaleza de quienes pactan y otro que pone de relieve la naturaleza del acto de institución. Esta operación lleva a ver la unión tanto como "pueblo" -en un sentido específico que luego veremos- cuanto, por otro lado, como "asociación" o "cuerpo político". Es decir, a distinguir o reconocer dos "aspectos" o "momentos" del todo unitario que ella constituye. En efecto, en el Libro I del Contrato Rousseau se refiere a ambos, aunque deja en un plano secundario -pero no olvidando- el aspecto de pueblo, para poner su atención en el aspecto de asociación de la unión. En los Libros II y III desarrolla en un plano teórico general los conceptos correspondientes a esta mirada, en particular, los de república, soberanía, voluntad popular y gobierno. Con estas indicaciones, veamos las distintas determinaciones de la unión.

\footnotetext{
${ }^{4}$ Así por ejemplo, respecto de la "voluntad general" Riley (1970: 86) ha dicho que es "una contradicción en los términos". Según este autor, ese término expresaría la imposibilidad del esfuerzo de Rousseau de unir la idea de la "moralidad del bien común", propia de las ciudades antiguas, con la "moderna visión individualista de que toda vida política es convencional” (Riley, 1999: 102).
} 
La definición de república legítima supone que un pueblo existe y que "el acto por el cual un pueblo se constituye en tal... es el verdadero fundamento de la sociedad" (CS, I; v: 8). Por hipótesis, este acto es el contrato de todos con todos (CS, I; vi: 9). Un pueblo se distingue de una mera "agregación" o "agrupación" de hombres -es decir, de un simple conjunto- por el hecho de que constituye una unidad, una "unión" (CS, I: v: 8). 5 En otras palabras, un "todo".

El contrato crea la "unión" como figura diferenciada de los miembros, aunque vinculada a ellos (CS, I; vi: 9). "Al instante, en lugar de la persona particular de cada contratante, este acto de asociación produce un cuerpo moral y colectivo compuesto de tantos miembros como votos tiene la asamblea, el cual recibe de este mismo acto su unidad, su yo común, su vida y su voluntad" (CS, I; vi: 10. N. T., Rousseau, 1997: 183). ${ }^{6}$ Siguiendo una antigua tradición, pero en particular a Hobbes, Rousseau piensa la unión por analogía con el cuerpo humano (CS, II; iv: 16; CS, III; i: 30). Ella constituye un "cuerpo artificial" (CS, III; i: 33), al que le imputa vida, identidad, fuerza, intereses y voluntad. Aunque a diferencia de los hombres la unión es una persona moral que surge a la vida por el acto de asociación, se asemeja a ellos en que "comienza a morir desde su nacimiento, llevando en si los gérmenes de su destrucción” (CS, III; xi: 48).

Como señalamos, la unión puede verse desde perspectivas diferentes: por un lado, como "asociación", "cuerpo político" o "república"; y por otro, como "pueblo", ahora en el sentido más específico de conjunto de "hombres" tomados como miembros o partes de un todo unitario (Cuéllar y Bolívar, 2001). "La persona pública que se constituye así, por la unión de todas las demás, (toma) ahora el nombre de República o cuerpo político, el cual es denominado por sus miembros Estado cuando es pasivo, Soberano cuando es activo, Potencia, al compararlo con sus semejantes. En cuanto a los asociados, ellos toman colectivamente el nombre de pueblo, llamándose en particular Ciudadanos como partícipes de la autoridad soberana y Súbditos como sometidos a la ley del Estado" (CS, I; vi: 10. N. T., Rousseau, 1997; 183-184).

Considerada en su aspecto de asociación o república, la unión es una "persona moral", una "persona pública" y más precisamente, un "ente de razón" (CS; I; i: 11). Con esto, el autor no sólo destaca el carácter racional del acto de pactar y de su

\footnotetext{
${ }^{5}$ En la Primera versión del Contrato social o Ensayo sobre la forma de la República, escrita poco antes de la definitiva (Derathé, 1997: 23-24): dice: "Hay mil maneras de juntar a los hombres, pero no más que una de unirlos (subrayado nuestro). Es por esto que en esta obra yo no doy más que un método para la formación de sociedades políticas, aunque en la multitud de agregaciones que existen actualmente con ese nombre no hay tal vez dos que hayan sido formadas de la misma manera y ni una que lo haya sido de acuerdo con lo que establezco. Pero yo busco el derecho y la razón y no disputo hechos" (Rousseau, 1997: 119). La tesis del pacto, más que hipótesis, es un principio de inteligibilidad de lo real o como dice Kant (1993), una "simple idea de la razón" (sobre esto, ver Goyard-Fabres, 1996: 155-177).

${ }^{6}$ La versión española que usamos tiene un error: "Este acto de asociación convierte al instante a la persona particular de cada contratante en un cuerpo normal y colectivo...".
} 
resultado sino también, en consecuencia, del tipo de intereses y de voluntad que le imputa a la asociación. Esta existe como medio para procurar el bien de todos (seguridad, libertad e igualdad) y se compone por todos los asociados considerados en su aspecto racional, como iguales. En efecto, aunque los hombres, por naturaleza, pueden "ser desiguales en fuerza o en talento", por el pacto vienen a ser todos iguales "por convención y derecho" (CS, I, ix: 13. Ver también CS, I; viii: 11; CS, II, iv: 17). En esta óptica, que los ve como ciudadanos a la vez que súbditos, actúan (deberían actuar) orientados por la razón y el "buen sentido" (CS, II, iv: 17 y CS, IV; i: 55). En un plano general, esto también define el concepto de virtud ciudadana o simplemente "virtud" (CS, III; iv: 36), a la que se refiere cuando pasa al nivel de los referentes históricos.

La fuerza de la unión - de la asociación- está pensada como la suma de las fuerzas de sus miembros (CS, I; vi: 9). Su interés consiste en la preservación de estos, así como del todo que en conjunto constituyen (interés general o bien común) (CS, II; iv: 16; v: 18; CS, III; ix: 45).

Asimismo, Rousseau le atribuye voluntad, que vincula directamente con los intereses. ${ }^{8}$ La voluntad del cuerpo político es general, en el sentido de que "parte de tomar en cuenta los intereses de todos los miembros, para referirse a ellos de manera general" (CS, II; iv: 17; CS, IV, ii: 57). Por consiguiente, ella "sólo atiende al interés común" (CS, II; iii: 16). "Lo que generaliza la voluntad no es tanto el número de votos cuanto el interés común que... une (a los miembros)" (CS, II; iv: 17). Así, la voluntad general está determinada por la propia naturaleza de la asociación, y consiste en la persecución racional de esos intereses en cuanto generales.

Pero la unión puede verse también desde el punto de vista de los asociados considerados no sólo en su aspecto racional -como ciudadanos y súbditos-, sino en la totalidad de su ser, es decir, como "hombres": "...además de la persona pública, tenemos que considerar las personas privadas que la componen, cuya vida y libertad son naturalmente independientes de ella. Se trata, pues, de distinguir debidamente los derechos respectivos de los ciudadanos y del soberano, y los deberes que tienen que cumplir los primeros en calidad de súbditos, del derecho que deben gozar como hombres" (subrayado nuestro. CS, II; iii: 16; ver también CS, II; vii: 11).

Así, el pacto no sólo instituye a la asociación y al Estado, sino también, como otro aspecto de la unión, al "pueblo", en cuanto unidad vinculante de tradiciones y

\footnotetext{
${ }^{7}$ Hay que tener presente que mientras Montesquieu (1971, Libro III, cap. iii), atribuye la virtud a la democracia, Rousseau sostiene que ella es el fundamento de toda soberanía legítima, es decir, también de la aristocracia y la monarquía basadas en el principio de soberanía popular (CS, III, iv: 36). Sobre esto, más adelante.

${ }^{8}$ Rousseau no define qué entiende por voluntad, pero es claro que la ve como la disposición de la acción en cuanto orientada a la realización de los intereses o como la acción orientada a la realización de los intereses. Cotéjese con Hobbes (1984; 48), para quien ella es "último apetito o aversión inmediatamente próximo a la acción u omisión correspondiente... acto (y no facultad) de querer". Sobre esto, ver Riley (1999).
} 
sentimientos, en otros términos, como comunidad (ver Sur l'Économie Politique, en Rousseau, 1996). Lo que distingue a la unión considerada como pueblo es el hecho de que en su determinación se tiene en cuenta las costumbres, tradiciones y sentimientos de los miembros, es decir, el "lazo social" que los une (CS, II; ix: 25), aspectos que cuando se la considera como asociación quedan si no excluidos, en todo caso obscurecidos por el privilegio dado a la razón y al "buen sentido".

Adviértase que con esto Rousseau reconoce que cada persona de hecho tiene sus propios intereses y su propia voluntad, que no necesariamente coincidirán con el interés general ni con la voluntad general: "cada individuo puede, como hombre, tener una voluntad contraria o desigual a la voluntad general que posee como ciudadano: su interés particular puede aconsejarle de manera completamente distinta de la que le indica el interés común..." (CS, II; vii: 11). En esta conexión, refiriéndose a los magistrados o miembros del gobierno, Rousseau distingue tres tipos de intereses y de voluntades "esencialmente diferentes: la voluntad propia del individuo, que no atiende sino a su fin particular; la voluntad común de los magistrados, que se relaciona únicamente con el bien del príncipe (la institución del gobierno) y que podemos llamar voluntad de corporación, la cual es general con respecto del gobierno y particular con respecto al Estado de que forma parte... y la voluntad del pueblo o voluntad soberana, que es general tanto con relación al Estado considerado como el todo, como con respecto al gobierno establecido como parte del todo" (CS, III; ii: 33-34).

La consecuencia de estas distinciones es que la unión -como pueblo, pero también como asociación o república- siempre tendrá que enfrentar una tensión entre los intereses de los miembros considerados como "hombres" (intereses particulares) o como miembros del gobierno (intereses de corporación), por una parte y los que deberían tener cuando se los considera como ciudadanos (intereses generales), por otra.

Por último, señalemos que la tendencia al conflicto entre la voluntad particular y la general no sólo deriva de que los hombres no son "entes de razón", sino también de que difieren en el grado de racionalidad o de virtud (CS, I; vii: 11). Por ello, Rousseau puede decir que si bien "el pueblo (en el sentido de "vulgo") quiere siempre el bien, no siempre lo ve" y que el juicio que dirige la voluntad de los individuos "no es siempre esclarecido" (CS, II; vi: 21).

\section{Los principios de la "república legítima"}

Una vez establecida la determinación inicial del todo que la unión constituye, Rousseau procede al tratamiento de su aspecto de asociación o cuerpo político (Libro I, caps. vii a ix) y de sus atributos propios, expresados en los conceptos de república legítima, de soberanía y de voluntad general (Libro II, caps. I a vi y luego, xi y xii), para luego, en el Libro III referirse al gobierno. En esta exposición dejaremos de lado la discusión específica de los conceptos de soberanía y de voluntad popular, para 
privilegiar el conjunto de determinaciones según su orden lógico.

En cuanto suma del poder de todos, la persona moral de la asociación -es decir, la república o Estado- es el máximo poder en ella, por consiguiente, es soberana. Además, por su constitución y composición, su soberanía es popular. Como señalamos antes, esta es una consecuencia necesaria de la forma como Roussseau redefine el pacto social y significa una transformación radical de la manera como se entiende y define el concepto de soberanía en otras versiones de la teoría del contrato. En efecto, puesto que el acto de institución es un pacto de todos con todos tomados como iguales, la unión que surge es una persona colectiva compuesta por todos los asociados sin distinción de rangos. Por consiguiente, es esta persona colectiva quien es soberana. Ella se constituye como tal por el acto mismo de su institución, sin más, es decir, sin que sea necesario para su "perfeccionamiento" que antes se establezca el gobierno. Por el contrario, en las distintas versiones de la teoría del contrato, la "comunidad natural" preexistente -o bien, la asociación que surge del pacto- se "perfecciona" (llega a ser propiamente un "pueblo" o se "constituye" como tal) cuando tiene o se da un gobierno (ver, por ej. Suárez, 1963; Pufendorf, 1998; Locke, 1966; Hobbes, 1984. Asimismo, ver Terrel, 2001: 367 y ss.; y Cuéllar y Bolívar, 2001).

De esta manera, Rousseau establece el concepto de soberanía poniéndolo de acuerdo con la tradición republicana. La soberanía es popular o simplemente no es más que fuerza o imposición no legítima. En efecto, para Rousseau, la persona moral de la república, constituida en asamblea de ciudadanos, es el titular de la soberanía y en esta condición ejerce la función legislativa, encargada de determinar la voluntad general. Por otra parte, y puesto que la voluntad general "lo es del cuerpo del pueblo..., la voluntad declarada es un acto de soberanía y hace la ley" (CS, II; ii: 14. N. T, Rousseau 1997: 191). En otras palabras, esta, por su propia naturaleza, sólo puede referirse a los ciudadanos de modo general (CS, II; iv: 18), lo que significa, como lo ha subrayado Terrel (2001: 349 y 362) que "el soberano actúa exclusivamente legislando".

Pero por otra parte, es necesario que se aplique la ley. La aplicación es un acto particular que no corresponde a la asamblea legislativa -al soberano- sino al gobierno (CS, II; i: 30-31). Este lo hace usando la fuerza soberana de la cual es depositario. Así, Rousseau no sólo distingue la función legislativa de la ejecutiva, sino que también subordina esta última a la primera, en correspondencia con la distinción de los papeles de ciudadano y súbdito de los miembros.

Esto define el principio de la soberanía popular, que incluye (i) el de soberanía del pueblo (de la asociación), encarnado en la asamblea legislativa, compuesta por los asociados en su calidad de ciudadanos. En ella reside el poder legislativo, cuya tarea es dictar la ley (declarar la voluntad general). Y (ii) el de primacía del soberano (de la 
asamblea legislativa) por sobre el poder ejecutivo (el gobierno) (CS, III; i: 30-31). El soberano es el titular del poder de la unión, mientras que el gobierno es el depositario de dicho poder, con el único fin de aplicar y hacer cumplir la ley. Los magistrados o miembros del gobierno no son más que mandatarios del soberano; por consiguiente, este "puede limitar, modificar y resumir cuando le plazca... el poder que ha depositado en ellos" (CS, III; i: 31). ${ }^{9}$

Cualquiera sea la forma de gobierno, la república es legítima en tanto se basa en el principio de soberanía popular. Su legitimidad deriva del hecho de que los asociados, en cuanto ciudadanos, determinan lo que deben obedecer como súbditos. Es decir, del respeto a la libertad civil y moral, que no es otra cosa que "la obediencia a la ley" (CS, I; viii: 12).

Nótese que si en el del discurso teórico sobre la asociación y la soberanía la obediencia a la ley equivale al predominio de la voluntad general, en el plano de los referentes históricos a los que continuamente acude Rousseau, equivale a la "virtud". Es importante señalar que en este punto se distancia de Montesquieu (1971: Libro III, cap. iii), quien atribuyó la virtud sólo a la democracia. Para Rousseau, en cambio, ella es el fundamento de toda república legítima, independientemente de la forma de gobierno. En efecto, "siendo la autoridad soberana en todas partes la misma, el mismo fundamento debe ser el de todo Estado bien constituido, más o menos, es cierto, según la forma del gobierno" (CS, III; v: 36).

El soberano creado por el pacto puede darse distintas formas de gobierno. Las formas puras son la democracia, la aristocracia y la monarquía. La democracia se caracteriza porque el poder soberano confía "el depósito del gobierno a todo el pueblo o a su mayoría"; la aristocracia porque el poder ejecutivo se deposita "en manos de los menos", pudiendo llegar incluso "hasta un número insignificante indeterminado"; mientras que en la monarquía se "concentra todo el gobierno en un magistrado único de quien los demás (magistrados) reciben el poder” (CS, III; iii: 35).

Más allá del criterio numérico, Rousseau distingue propiedades específicas de las formas puras de gobierno, atendiendo a la manera como se estructura y compone el "príncipe" (el órgano ejecutivo) y al grado en que favorecen el juego de los intereses particulares. En breve, mientras que la democracia une las funciones legislativas y ejecutivas en el mismo "cuerpo político" (o el ejecutivo en uno separado, pero

\footnotetext{
${ }^{9}$ Para el sentido común de nuestro tiempo, esta formulación del principio de soberanía popular puede parecer obvia, pero en la época de Rousseau ciertamente no lo era, desde luego porque ella tendía a concebirse como un atributo del gobierno o del representante (el monarca). Esto también explica la importancia que da al tratamiento del gobierno, que ocupa un libro entero de su pequeño tratado, lo que no ocurre en otras versiones de la teoría del contrato. También puede llamar la atención que Rousseau no mencione el poder judicial ni la función correspondiente. Podemos suponer que ello se debe a que en el las monarquías europeas, dicha función se subsumía dentro de las competencias del gobierno (de la monarquía). contexto de la teoría del contrato social (salvo Locke) y de las prácticas de las monarquías europeas, dicha función se subsumía dentro de las competencias del gobierno (de la monarquía).
} 
compuesto por la mayoría de los miembros de la asamblea legislativa: CS, III: iv: 35), la monarquía los une en un solo individuo (CS, III: vi: 38), en tanto que la aristocracia electiva -es decir, "la aristocracia propiamente dicha"- las separa claramente en cuerpos distintos (CS, III; v: 37).

De esto resultan diferencias en los grados de concentración de la fuerza depositada en el gobierno, en el vigor, actividad y eficacia de este y en la forma en que favorece el desarrollo de los intereses particulares o de corporación en contra del interés general. Estos factores pueden afectar la subordinación que el gobierno debe a la asamblea legislativa. Puesto que la república legítima se define por la supremacía de esta, ella se disuelve cuando el gobierno sobrepasa sus límites y usurpa el poder legislativo. Entonces, "el abuso del gobierno, cualquiera él sea, toma el nombre de anarquía. Distinguiendo: la democracia degenera en oclocracia, la aristocracia "en oligarquía" y la monarquía "en tiranía" (CS, III; x: 47). Por último, aunque en principio Rousseau admite la monarquía como forma de gobierno legítima, luego la opone al "gobierno republicano", es decir a la democracia y a la aristocracia, tomando como importante criterio de diferenciación la existencia o no de elección de los gobernantes (CS, III; vi: 39).

En esta conexión, vale la pena destacar que, en su momento inicial, y en plena congruencia con las características del acto que da origen a la unión, toda república legítima es una democracia. En efecto, tan pronto se instituye la asociación o república, la asamblea legislativa establece la forma de gobierno. Este, su primer acto, supone que el cuerpo político surge a la existencia reuniendo las dos funciones -legislativa y ejecutiva- en la asamblea legislativa. "Aquí se descubre una de esas sorprendentes propiedades del cuerpo político, por las cuales concilia operaciones contradictorias en apariencia, puesto que esto se efectúa por una súbita conversión de la soberanía en democracia, de suerte que, sin ningún cambio sensible y sólo por una nueva relación de todos a todos, los ciudadanos, convertidos en magistrados, pasan de los actos generales a los particulares y de la ley a la ejecución" (CS, III; xvii: 53).

\section{Podemos resumir los principios substantivos de la república legítima}

(a) ella es la forma de organización política que se da un pueblo -término este que aquí denota la unión o "cuerpo colectivo" surgido del contrato- y que, aunque se compone de los asociados, es distinto de estos; (b) la unión se presenta tanto en la forma de "asociación" o república" como de "pueblo", este término ahora entendido en el sentido de unión de los hombres que han pactado; (c) vista como asociación, es un "ente de razón", más precisamente, una persona moral que tiene identidad, fuerza, intereses y voluntad. Sus intereses y su voluntad son generales, tanto en el sentido de que "parte(n) de tomar en cuenta los intereses de todos los miembros" y de la unión como tal (interés general o bien público), como de que se refiere(n) a ellos "de manera 
general". Al mismo tiempo, en cuanto "pueblo" la unión es una persona moral unida por costumbres, tradiciones y sentimientos; (d) la persona pública de la asociación o república es soberana, es decir, es el máximo poder en la asociación, y su voluntad es autónoma. Por su naturaleza, el ejercicio de la soberanía exige distinguir entre el momento de la determinación de la voluntad y el de su aplicación (funciones legislativa y ejecutiva). La asamblea de los ciudadanos es el titular de la soberanía, pero su función se limita a determinar la voluntad general; por tanto, es el poder legislativo. (e) El poder de la república se deposita en el gobierno, titular del poder ejecutivo, que es un comisionado de la asamblea legislativa, con el sólo propósito de hacer cumplir la ley, subordinándose a ella. La asamblea legislativa puede darse la forma de gobierno que estime adecuada. Las formas de gobierno varían en la manera como se estructuran y componen y en el grado en que favorecen el juego de los intereses particulares (individuales y/o de corporación).

\section{Sobre los principios de composición de la república como un todo}

Hasta aquí hemos presentado la secuencia lógica del argumento que, partiendo con el contrato de todos con todos, primero define su resultado como unión, distinguiendo entre los aspectos de "pueblo" y de asociación o "cuerpo político", dependiendo de si se atiende a la naturaleza de quienes pactan o a la naturaleza del acto de pactar. En un segundo momento, el argumento desarrolla el concepto de asociación o cuerpo político y de sus atributos, soberanía popular y voluntad general. Con esto, Rousseau precisa los principios substantivos del derecho político que definen la idea de "república legítima" (Estado). Tomemos nota también de que, en especial en la última parte de la secuencia, la argumentación se sitúa en un alto nivel de generalidad y abstracción, de suerte que el tratamiento del aspecto de asociación o cuerpo político exige pensarla como instancia de lo racional. En efecto, ya vimos que el criterio que lleva a distinguir lo propio de la asociación como forma de organización política deriva de destacar la naturaleza racional del acto de pactar; por ello, se presenta como persona moral y como "ente de razón". En consecuencia, la determinación de su concepto y atributos no puede operar sino en el plano del discurso racional, con actores del mismo carácter. La república legítima es pues una idea, tanto en el sentido de ideal racionalnormativo como de principio de comprensión y ordenamiento de lo real.

De acuerdo con lo señalado en la introducción, corresponde ahora preguntarse por los principios formales o metodológicos a partir de los cuales Rousseau piensa la unión como un "todo". En esta tarea, vamos más allá de los enunciados formales y explícitos del autor, dejando si se quiere, de lado o en un segundo plano los contenidos substantivos de su argumentación, para destacar los aspectos formales de composición de la idea de unión como "todo". Aunque sin duda esta operación es parte de la tarea de "reconstrucción", no es ajena al autor. En efecto, sobre todo en el Libro III él usa 
frecuentemente el término; además, y aunque ello no sea inmediatamente claro por el orden que da a su exposición, Rousseau separa el tratamiento del "todo" considerado en si mismo, del que corresponde al análisis de las relaciones que mantiene (o debería mantener) con el ambiente natural y humano en que se instituye. ${ }^{10}$

En esta sección nos referiremos sucintamente a dichos principios de composición, distinguiendo entre los relativos a la naturaleza y forma del todo, para al final presentar el modelo de su "estado de equilibrio".

\section{Principios sobre la naturaleza del todo}

Rousseau parte de un principio general que destaca el carácter de totalidad de la unión. En efecto:

1. Ella es un todo compuesto y complejo que se integra por partes o elementos subtotalidades- de diferente nivel de cohesión y concreción, es decir, por elementos "simples" (individuos, hombres) y compuestos (órganos). Los órganos son "cuerpos" o todos parciales, compuestos por individuos y subordinados al todo mayor. Los individuos son personas naturales, cada una síntesis singular de razón, sentimientos, apetitos (Cuéllar y Bolívar, 2001).

2. La existencia e identidad del todo (de la unión) reposa en lo que une a los miembros individuales, es decir, en el interés que comparten ("interés público" o "bien común"). O desde otra perspectiva o nivel de análisis -y no contradictorio-, en los valores en que sus miembros creen y que derivan de tradiciones, costumbres y sentimientos compartidos. Este es el "lazo social" que los une (CS, II; ix: 25), sin el cual el todo deja de existir como tal.

3. El todo puede analizarse destacando distintos aspectos de su complejidad. Pero al hacerlo no debe olvidarse su unidad, que ha de ser recuperada después.

3. 1. En un primer momento, Rousseau destaca los aspectos que presenta el todo cuando se considera su modo de constitución y las características de los miembros individuales que lo constituyen. Con ello se pone de relieve la naturaleza del acto constitutivo y a la naturaleza de los individuos que se asocian. Desde este punto de vista, el todo se presenta como asociación o república a la vez que como pueblo. Lo primero resulta de poner el acento en el carácter racional del acto de pactar y de su

$10 \quad{ }^{10}$ El tema de las relaciones entre el todo y su ambiente lo plantea en los capítulos vii a x del Libro II del Contrato, inmediatamente después de los capítulos destinados a definir los conceptos de soberanía y de "voluntad general" y a dar cuenta de sus atributos. Asimismo, vuelve sobre él en los últimos capítulos del Libro III, dedicado al gobierno, y en el Libro IV. 
resultado, mientras que lo segundo, de recuperar la complejidad de los asociados en cuanto hombres, síntesis compleja cada uno de razón, sentimientos y apetitos.

3. 2. Un segundo momento surge al considerar separadamente el aspecto de asociación o república. Entonces destacan las funciones que deben cumplirse y los órganos encargados de realizarlas. Algunas funciones las realizan órganos colectivos y otras las realizan los miembros individuales desempeñando distintos papeles (ciudadano, súbdito, magistrado).

3. 3. En concordancia con la filosofía precedente y los principios del derecho político, en el nivel más general la distinción de funciones puede reducirse a las de mando y de obediencia.

3. 4. Sin embargo, no hay una correspondencia unívoca entre esta distinción y la que separa los órganos en colectivos e individuales. Las funciones generales de mando y de obediencia incluyen dentro de si un principio de ordenación y articulación que reproduce la distinción "mando-obediencia" en cada una de ellas. En efecto (i) la función general de mando se divide en legislativa y ejecutiva colocando a la segunda bajo la dirección de la primera (el ejecutivo debe obediencia al legislativo); (ii) en la realización de la función general de obediencia concurren los papeles ordenados de ciudadano y súbdito de los miembros individuales (el individuo como ciudadano decide lo que luego obedece como súbdito).

3. 5. La función global de mando que realiza el todo en cuanto república consiste en el ejercicio de la soberanía, y sus momentos específicos son las funciones legislativas y ejecutivas. Los órganos encargados de estas son la asamblea legislativa o asamblea de ciudadanos y el gobierno, respectivamente. Es importante destacar (i) que los miembros, en su papel de ciudadanos, en conjunto componen el órgano legislativo (la asamblea legislativa), participando en la realización de la función legislativa. Asimismo (ii) como individuos o como cuerpo, desempeñan la función ejecutiva, variando el número de quienes lo hacen según la forma de gobierno establecida (el rango va de uno a todos: CS, III; iii: 35 ).

3. 6. Por último, la función de obediencia o de acatamiento de la voluntad general, de la ley, corresponde a los miembros en su calidad de súbditos. Sin embargo, esta función exige el concurso del gobierno que por ello es "un cuerpo intermediario entre los súbditos y el soberano" (CS, III; i: 31).

\section{Principios sobre la forma del todo}

En relación con la forma del todo, interesa el equilibrio que logra y que define su existencia. El análisis del equilibrio del todo puede hacerse aislándolo, por así decir, de su ambiente o "clima" (en el sentido que a esta expresión da Montesquieu), o tomando a este en cuenta. 
4. Toda totalidad compuesta y compleja y en particular la república, tiene un punto o más precisamente, un rango óptimo de equilibrio, que define tanto su forma propia como su persistencia, de suerte que si aquél no se logra o si se altera, el todo tendrá problemas. En términos substantivos, que el todo se encuentre en equilibrio significa que entre los miembros prima el respecto al bien común y a la voluntad general o, en otros términos, que el lazo social es fuerte.

4. 1. El equilibrio del todo depende del equilibrio que guarden las relaciones entre sus partes. Si sólo se lo considera desde esta perspectiva, dejando de lado el "clima", el equilibrio se logra cuando hay igualdad en la fuerza de cada parte o, como dice Rousseau, "cuando hay igualdad entre el poder del gobierno, considerado en si mismo, y el poder de los ciudadanos, soberanos por un lado y súbditos por el otro" (CS, III; i: 31). ${ }^{11}$ Como dijimos, en el caso de la república, desde un punto de vista sustantivo esto significa que prevalece el bien común y que se respeta la voluntad general: el lazo social es fuerte.

4. 2. Por otro lado, cuando se toma en cuenta el ambiente, el equilibrio en las relaciones entre las partes $\mathrm{y}$, por consecuencia, del todo, depende del grado en que este se adecua a las características del medio natural y humano en que se instituye o, en palabras de Montesquieu, del "clima". La adecuación puede ser mayor o menor y puede afectar tanto la fortaleza del lazo social como la forma y desempeño del gobierno (CS, II; ix: 25; y II; x: 26). Idealmente, cuando hay equilibrio entre el todo y su ambiente, la república alcanzará su "máximum" de fuerza (CS, II; x: 26), lo que significa que será (i) autosuficiente; (ii) que el lazo social será fuerte y (iii) que la forma de gobierno será congruente con las características y necesidades de la población. Estas condiciones favorecen el logro del equilibrio (igualdad) en las relaciones entre las partes $\mathrm{y}$, por ende, del mismo todo.

En lo que sigue nos referiremos a las relaciones entre las partes componentes, dejando el papel del clima para otro momento (Bolívar y Cuéllar, 2007). En esta perspectiva:

4. 3. El equilibrio es precario o puede perderse cuando el lazo social es débil o se debilita. En general, ello puede ser resultado (i) del juego de los intereses particulares, que son propios de la naturaleza de los hombres. Por otra parte (ii) dicho juego puede verse favorecido por la forma de gobierno que se establece. En esta conexión (iii) además, el mismo carácter compuesto del todo contiene una tensión interna que los otros factores pueden desatar. La tensión consiste en que siendo una suma de fuerzas, el todo es necesariamente una fuerza mayor a la de cada uno de los miembros individuales que lo componen. Según esto, mientras mayor su tamaño (número de miembros

\footnotetext{
${ }^{11}$ Después del libro I, en que distingue claramente la fuerza del derecho, en sus análisis Rousseau hace implícitamente equivalentes la fuerza, el poder y la autoridad. Dejaremos de lado la discusión sobre los significados de estos conceptos ya que nos desviaría de nuestro objetivo.
} 
individuales) menor la contribución relativa (el poder relativo) de cada individuo y menor su grado de libertad (en palabras del autor, "más la libertad disminuye": CS, III; i: 31$).{ }^{12}$

4. 4. Frente a situaciones de desequilibrio que afectan la unidad del lazo social, esto es, el equilibrio del todo, este puede reaccionar operando directamente sobre el gobierno y/o sobre los súbditos. En efecto, (i) puede "concentrar" el gobierno o por el contrario, dividirlo en órganos individuales o colectivos distintos. La concentración y la división del gobierno pueden combinarse y tener carácter temporal o no. ${ }^{13}$ Asimismo, (ii) puede operar sobre los súbditos recurriendo a la educación y a la religión civil, con el fin de fortalecer el "amor patrio" y la virtud ciudadana (CS, IV; viii: 73-74). En principio, ambos modos de acción pueden coexistir.

También puede darse el caso de que dos o más todos autónomos se unan en una confederación para sumar sus poderes y constituir un todo mayor. Pero esta posibilidad está solamente mencionada y no analizada en el Contrato, por lo que no la consideramos aquí.

\section{El modelo del estado de equilibrio}

Hasta aquí el enunciado de los principios de composición de la unión como un todo, con especial atención a su aspecto de asociación (como república o Estado). Estos principios subyacentes adquieren plenitud en el desarrollo de su teoría de la república legítima y por ello, también en la formulación de una imagen o modelo de su estado de equilibrio. Explicitar este modelo resulta útil, primero, porque permite evaluar no sólo qué tan coherente es la teoría sino también qué tan adecuado es el proceso de "reconstrucción-reconstrucción". Y luego, y no menos relevante, porque ella es la base sobre la cual reposan y adquieren sentido los enunciados de orden más bien sociológico que Rousseau asienta en la forma de un sistema de hipótesis sobre el funcionamiento del Estado. Aunque aquí no desarrollamos este último tema, es importante al menos mencionarlo para dar una idea más clara del sentido y papel de la imagen del estado de equilibrio. Veamos brevemente en que consiste.

\footnotetext{
${ }^{12}$ Aquí Rousseau piensa en la libertad natural que cada miembro tiene como hombre y no en la libertad civil y moral que depende, precisamente, de su subordinación al orden político y moral establecido con la creación de la persona moral de la asociación. Esta interpretación adquiere sentido cuando se advierte que el enunciado que citamos se ubica en el nivel de análisis correspondiente al sistema de hipótesis referido al estudio del funcionamiento del Estado, que no tratamos en este artículo (ver Bolívar y Cuéllar, 2007).

${ }^{13}$ El gobierno se concentra disminuyendo su tamaño, cambiando de forma (por ej., de la democracia a la aristocracia), suspendiendo su propia acción y nombrando funcionarios especiales en su lugar, uniendo las funciones legislativas y ejecutivas de modo temporal en una instancia provisional excepcional especial (tribunado, dictadura: CS, IV; vi: 66-68). Si debido al debilitamiento del lazo social, el gobierno ha aumentado en exceso su concentración y poder relativo, amenazando así el equilibrio general de la república, se lo puede dividir de manera temporal o permanente.
} 
En la perspectiva que centra la mirada en las relaciones entre las partes haciendo abstracción del ambiente y de las variaciones en la forma concreta en que las repúblicas se adecuan a él, adquieren relieve las funciones, los órganos encargados y su composición. Importan tres tipos de relaciones genéricas: (i) la relación "del todo con el todo", es decir, del soberano con los miembros (ciudadanos, súbditos); (ii) la del todo con el gobierno, en cuanto cuerpo "intermediario" entre el soberano y los súbditos; y (iii) la del gobierno con los miembros (súbditos, ciudadanos) (CS, II, xii: 29 y CS, II; xiii: 30 ).

Por la misma definición de la asociación o cuerpo político, la función de dictar la ley es propia de la asamblea legislativa, titular de la soberanía, mientras que la del gobierno es hacerla cumplir. Para ello, este concentra el poder soberano (la fuerza de la asociación). Rousseau indica que, en principio (en su forma ideal), esto significa que (i) el poder total del gobierno es igual al del soberano (el cuerpo político). Pero dado que el soberano se compone de los miembros en su papel de ciudadanos, ello equivale a decir (ii) que el poder (sumado) de estos es igual al poder del gobierno y que lo mismo ocurre si se los toma como súbditos. Por otra parte, al considerar a los miembros sólo como súbditos, su contribución al equilibrio global depende del grado en que su conducta se adecua a lo que decidieron como ciudadanos. Por consiguiente (iii) mientras mayor la adecuación -es decir, mientras mayor la preponderancia de la voluntad general o mayor la fortaleza del lazo social-, mayor la probabilidad de que el equilibrio global se mantenga (que siga predominando la voluntad general y, en consecuencia, que el gobierno se atenga a los límites de su cometido).

Así, la relación entre las partes alcanza su óptimo cuando la voluntad general domina completamente a las voluntades particulares (en su forma individual o de corporación), es decir, cuando cada parte cumple la función que le es propia. ${ }^{14}$ Por ello Rousseau puede decir que "no se podría alterar ninguno de los tres términos sin romper al instante la proporción. Si el cuerpo soberano quiere gobernar, si el magistrado desea legislar o si los súbditos se niegan a obedecer, el desorden sucede al orden, y no obrando la fuerza y la voluntad de acuerdo, el Estado disuelto cae en el despotismo o en la anarquía (CS, III; i: 31).

Si además incluimos la relación entre el todo y su ambiente (mencionada en el apartado 4. 2. de esta sección), se puede plantear la siguiente hipótesis general: si hay adecuación entre el todo y el medio en que se establece, la república será proporcionada y podrá si no alcanzar, al menos aproximarse a su "máximum" de fuerza. Entonces el

\footnotetext{
14 "En una legislación perfecta, la voluntad particular o individual debe ser nula; la voluntad del cuerpo, propia del gobierno, muy subordinada, y por consiguiente, la voluntad general o soberana, siempre dominante y pauta única de todas las demás". A continuación, Rousseau añade que "en el orden natural, por el contrario, estas distintas voluntades se hácense más activas a medida que se concentran. Así, la voluntad general es siempre la más débil, la del cuerpo ocupa el segundo lugar y la particular el primero de todos" (CS, III; ii: 34).
} 
lazo social será fuerte, lo que significa que el grado de reconocimiento del interés general o bien común será alto y, por tanto, también el acatamiento a la voluntad general. En estas condiciones, la probabilidad de que exista equilibrio en las relaciones entre las partes es alta y en consecuencia, la república se encontrará dentro del rango óptimo de equilibrio.

Esta hipótesis general establece el puente que facilita conectar sus enunciados sobre la república legítima, correspondientes al plano más general y abstracto del análisis, con su preocupación por llevar más allá la mirada, es decir, a un plano de menor abstracción que, al incluir el papel del ambiente y el juego de los intereses particulares, permita estudiar el funcionamiento del Estado considerando a los hombres "tal como ellos son y a las leyes tal como pueden ser". Pero adentrarse en este plano de análisis supone examinar los factores que pueden llevar a alterar el equilibrio entre las partes, lo que está fuera de los límites de este trabajo.

\section{Final}

En este artículo nos propusimos revisar el Contrato social de Rousseau aceptando su declaración de que es un "pequeño tratado" sobre los principios del "derecho político" y de la "república legítima", elaborado desde una perspectiva interesada no sólo por considerar a los hombres tal como deberían ser sino también como de hecho son, circunscribiéndonos al plano más abstracto y general de su análisis. En particular, nos interesamos por los principios formales o de composición, desde las que piensa al Estado como un todo y por las operaciones que le llevaron a establecer los principios constitutivos de la "república legítima". Ello exigió realizar una operación de "reconstrucción-reconstrucción" del discurso que, al tiempo que puso de relieve la importancia de su imagen de la unión como "todo" y de la distinción entre niveles de abstracción, permitió identificar la imagen o modelo del Estado en equilibrio.

En esta conexión y aunque no es un tema que hayamos desarrollado aquí, plantearse la elaboración de la teoría de la república legítima pensándola desde un principio de totalidad, le permitió sentar las bases para pasar del nivel del discurso filosófico político al de su aplicación para la interpretación de los fenómenos históricopolíticos. De esta manera, puede decirse que contribuyó al establecimiento de una mirada sociológica para el estudio del funcionamiento del Estado y del gobierno que muestra el hondo influjo de la obra de Montesquieu pero también, la enorme fortaleza de su inteligencia y creatividad. Esta es una de las razones que seguramente tuvo en mente Lévy-Strauss (1987) para considerarlo un "fundador de las ciencias del hombre".

En una visión más general, vale la pena subrayar que la innovación de Rousseau consistió en someter a crítrica la teoría del contrato partiendo de los mismos principios en que ella se basaba para re-estructurarla, ahora como teoría de la república legítima, 
mediante la fusión de la idea de soberanía con los principios de la tradición republicana (Terrel, 2001). El procedimiento fue cambiar las cláusulas del contrato, eliminado la subordinación de los ciudadanos a otro superior a ellos (el soberano de la tradición monárquica o el "representante de Hobbes) para colocarlos en cuerpo como soberanos.

Con ello, no sólo el pacto convierte a una mera "agrupación" en "unión”, es decir en una persona moral fundada en principios de razón, en un todo, sino que pasa a primer plano el vínculo que une a los miembros como esencia de la persona moral. Distinguiendo: en el nivel de análisis que corresponde a la elaboración de la teoría de la república legítima, adquiere relieve su carácter racional, que bien expresa la idea de voluntad general, pero cuando se pasa al plano de los referentes históricos tiene pleno sentido conceptuarla como "lazo social" basado en costumbres, tradiciones y sentimientos, es decir, en el horizonte moral en que operan la razón y el buen sentido. Esto, junto con la distinción entre aspectos o momentos de la unión (asociación a la vez que pueblo) muestran la realización del propósito del autor de considerar "a los hombres tal cual ellos son y a las leyes tal cual pueden ser". En efecto, aunque los hombres no son entes de razón, pueden ser razonables aunque también, víctimas de la inclinación a perseguir sus propios intereses por sobre los intereses generales. Esto no obscurece la significación de pensar la voluntad general como expresión del punto de vista de la razón -no universal sin más, sino tomando en cuenta el horizonte de la moralidad existente que enmarca el recurso al buen sentido. Desde este punto de vista no se trataría pues de un esfuerzo infructuoso por imposible de unir la idea de "moralidad el bien común" propia de la ciudad antigua "con la moderna visión individualista de que toda vida política es convencional", sino de una distinción no aclarada expresamente pero operante de hecho entre distintos planos de análisis.

Por último, y como quiera que sea, lo cierto del caso es que después del Contrato ya no sería posible pensar la soberanía sino como popular: decreto del fin de la soberanía basada en el derecho divino de los reyes o de la comunidad natural, a la vez que aseguramiento de la ciudadanía como fundamento de toda posible legitimación del poder político. En este sentido, el Contrato da forma a lo que existía como anticipación aún no realizada pero que muy pronto, con las revoluciones americana y francesa, se establecería para convertirse en un sentido común de la política y de su estudio en el mundo occidental: la república legítima es popular o simplemente no es república. 


\section{Bibliografía}

Bergeron, G. (1996), Tout était dans Montesquieu. Une relecture de L'Esprit des Lois. L'Harmattan, Col. Logique Juridique, Paris.

Bloom, A. (1993), "Jean-Jacques Rousseau", en L. Strauss y J. Cropsey, comps., Historia de la filosofía política, Fondo de cultura económica, México.

Bolívar A. y O. Cuéllar (2007), Rousseau sociólogo: acerca de su teoría sobre el funcionamiento de la república y del papel del gobierno, manuscrito no publicado, México.

Idem (2005), "La ubicuidad de lo político", en Revista de la Academia, núm.10 (págs. 337-357), Santiago, Chile.

Idem(2001), "Fundamentación y epitafio de la república democrática", Revista Argumentos, 39, agosto (págs. 95-115), México.

Derathé, R. (1997), “Introduction”, en J. J. Rousseau, Du Contrat social, précédé de Discours sur l'économie politique et de Du Contrat social, première version et suivi de Fragmentes politiques. Gallimard, Paris.

Derrida, J. (1967), De la Grammatologie. Les éditions du minuit, Paris.

Goyard-Fabres, S. (1996), La Philosophie du Droit de Kant. J. Vrin, Paris.

Hobbes, T. (1984), Leviatán o de la materia, forma y poder de una república, eclesiástica y civil. Fondo de cultura económica, México.

Kant, I., (1993), Metafísica de las costumbres. Ediciones Altaza, México-Barcelona.

Lévy-Strauss, C. (1987), "Jean-Jacques Rousseau, fundador de las ciencias del hombre”, en C. Lévy-Strauss, Antropología estructural, Siglo XXI (sexta edición), México.

Locke, J. (1966), Segundo Tratado del Gobierno Civil. Alianza, Madrid.

Montesquieu (1971), Del Espíritu de las leyes. Editorial Claridad, Buenos Aires.

Pufendorf, S. (1998), On the Duty of Man and Citizen. Cambridge University Press, Cambridge, U. K.

Riley, P. (1999), Will and Political Legitimacy. A Critical Exposition of Social Contract Theory in Hobbes, Locke, Rousseau, Kant and Hegel. Harvard U. Press, Cambridge, Mass. and London.

Idem (1970), “A possible explanation of the general will”, American Political Science Review, vol. LIXV, núm. 1, pp. 86-97.

Rousseau, J. J. (1986) El Contrato Social o Principios de Derecho Político. Editorial Porrúa, México.

Idem (1997), Du Contrat social, précédé de Discours sur l'économie politique et de Du Contrat social, première version et suivi de Fragmentes politiques. Gallimard, Paris.

Rubio Carracedo, J. (1990), ¿Democracia o representación? Poder y legitimidad en Rousseau. Centro de Estudios Constitucionales, Madrid.

Sabine, G. (1990), "El redescubrimiento de la comunidad: Rousseau”, en G. Sabine, Historia de la teoría política. Fondo de cultura económica, México.

Skinner, Q. (1993), Los fundamentos del pensamiento político moderno, Tomo I, El Renacimiento. Fondo de cultura económica, México.

Idem (1986), Los fundamentos del pensamiento político moderno, Tomo II, La Reforma. Fondo de cultura económica, México.

Suárez, F. (1963), Defensio Fidei III, Parte I, “Principatus Politicus o La Soberanía popular”. Consejo 
LA REPU̇BLICA LEGITIMA Y EL ORDEN POLITICO EN ROSSEAU: PRINCIPIOS DE LA COMPOSICIÒN EN

IMAGEN DEL ESTADO DE EQUILIBRIO, Págs. 239-260

( C EDITORIAL DE LA UNIVERSIDAD BOLIVARIANA DE CHILE, 2008

Superior de Investigaciones Científicas, Madrid.

Talmon J. (1955), The Origins of Totalitarian Democracy. Secker and Warburg, London.

Terrel, Jean (2001), Les théories du pacte social. Droit natural, souveraineté et contrato de Bodin á Rousseau. Éditions du senil, Paris.

Valenzuela Feijóo, J. (2006), Libertad y razón. Rousseau, Hegel y Marx. Lom Editores y UAM Iztapalapa, Santiago de Chile.

Idem (2003), Mercado, socialismo y libertad. Lom Editores, Santiago, Chile. 